\title{
Quantitative Pfirrmann Disc Degeneration Grading System to Overcome the Limitation of Pfirrmann Disc Degeneration Grade
}

\author{
Dae Cheol Rim \\ Department of Neurosurgery, Kim Young Soo Spine \& Joint Hospital, Seoul, Korea
}

\begin{abstract}
Objective: Pfirrmann disc degeneration grade is one of morphologic disc degeneration grading system and it was reliable on routine T2-weighted magnetic resonance (MR) images. The purpose of this study was to evaluate the agreement of Pfirmann disc degeneration grade, and check the alternative technique of disc degeneration grading system.

Methods: Fifteen volunteers ( 4 medical doctors related to spinal disease, 2 medical doctors not related to spinal disease, 6 nurses in spinal hospital, and 3 para-medicines) were included in this study. Three different digitalized MR images were provided all volunteers, and they checked Pfirmann disc degeneration grade of each disc levels after careful listening to explanation. Indeed, all volunteers checked the signal intensity of disc degeneration at the points of nucleus pulposus (NP), disc membrane, ligaments, fat, and air to modify the quantitative Pfirmann disc degeneration grade.

Results: Total 225 grade results of Pfirmann disc degeneration grade and 405 signal intensity results of quantitative Pfirmann disc degeneration grade were analyzed. Average interobserver agreement was "moderate (mean \pm standard deviation, $0.575 \pm 0.251$ )" from poor to excellent. Completely agreed levels of Pfirrmann disc degeneration grade were only 4 levels (26.67\%), and the disagreement levels were observed in 11 levels; two different grades in 8 levels (53.33\%) and three different grades in 3 levels (20\%). Quantitative Pfirrmann disc degeneration showed relatively cluster distribution with the interobserver deviations of 0.41-1.56 at the ratio of NP and disc membrane, and it showed relatively good cluster and distribution indicating that the proposed grading system has good discrimination ability.

Conclusion: Pfirmann disc degeneration grade showed the limitation of different interobserver results, but this limitation could be overcome by using quantitative techniques of MR signal intensity. Further evaluation is needed to access its advantage and reliabilities.
\end{abstract}

Key Words: Quantitative $\cdot$ Pfirrma disc grade $\cdot$ Disc degeneration $\cdot$ Magnetic resonance $\cdot$ Signal intensity

\section{INTRODUCTION}

The intervertebral discs are cylindrical, fibrocartilaginous, articulating structures connecting the vertebral bodies, and it can be divided microscopically into an outer annulus fibrosus surrounding a centrally located nucleus pulposus $(\mathrm{NP})^{13}$. These essentially mechanical intervertebral discs undergo changes with ageing and degeneration ${ }^{13)}$. Magnetic resonance imaging (MRI) is the most commonly used imaging modality for diagnosis of degenerative disc disease (DDD). And the most commonly used grading method by MR images was introduced by

- Received: June 29, 2015 • Revised: January 6, 2016

- Accepted: January 7, 2016

Corresponding Author: Dae Cheol Rim, MD, PhD

Department of Neurosurgery, Kim Young Soo Spine \& Joint Hospital,

15, Eonju-ro 174-gil, Gangnam-gu, Seoul 06017, Korea

Tel: +82-2-1577-5075, Fax: +82-2-3447-0015

E-mail: nsrimok@gmail.com

$\bigotimes$ This is an open access article distributed under the terms of the Creative Commons Attribution Non-Commercial License (http://creativecommons.org/licenses/by-nc/4.0/) which permits unrestricted non-commercial use, distribution, and reproduction in any medium, provided the original work is properly cited.
Pfirmann et al. ${ }^{7,818)}$. Pfirrmann disc degeneration grade used the signal intensity on T2-weighted MR images to estimate water content with morphological parameters on a scale from I to $\mathrm{V}^{8}$. This grading system is comprehensive and easily applicable with sufficient reproducibility ${ }^{12,13}$. But, this system proved relatively nondiscriminatory in elderly subjects and some ambiguity in categorizing disc degeneration ${ }^{10)}$.

Morphological changes including loss of height of the intervertebral disc, annular tears, intervertebral disc bulging and osteophyte formation and the biochemical changes of NP decrease signal strength has been believed to reflect the intervertebral disc degeneration ${ }^{15)}$. They are suitable for qualitative assessment, but they cannot easily be used for the quantitative evaluation ${ }^{14)}$. Indeed, the detection of the modification of the initial stage will be difficult because they will be displayed at a later stage of intervertebral degeneration. But the change in the signal strength of the $\mathrm{NP}$, which represents the biochemical changes, used for easily quantitative evaluation than the other parameters at an early stage ${ }^{14}$. The overall agreement rate of Pfirmann disc degeneration grade is excellently in the literatures ${ }^{8,12,13)}$. But, during the data collection in degenerative spine study, the Pfirrmann disc degeneration grade is very subjective method. The brightness and distinction of NP to disc 
membrane is the main difference between 5-graded Pfirrmann disc degeneration grade, but this categorization is easily be influenced by the different observers or investigators. In this study, the author tested interobserver reproducibility of Pfirrmann disc degeneration grade to determine this reliability. Furthermore, the application of quantitative signal intensity technique to supplement the possible limitation of Pfirmann disc degeneration grade.

\section{MATERIALS AND METHODS}

Fifteen volunteers were included in this study to investigate Pfirrmann disc degeneration grade and quantitative Pfirmann disc degeneration grade. The volunteers were composed as 4 medical doctors related to spinal disease, 2 medical doctors not related to spinal disease, 6 nurses in spinal hospital, and 3 para-medicines. The author explained to each volunteers about the purpose of this study, the medical usage of Pfirrmann disc degeneration grade, and the new concept of quantitative Pfirrmann disc degeneration grade by person to person. Sheets of brief medical information contained Korean translated description, table, the algorism and the sample images in original article were provided to all volunteers ${ }^{18)}$. After clear communication of this study, each volunteers were provided three different digitalized MR T2-weighted spine echo images (Fig. 1), and checked own considered Pfirrmann disc degeneration grade of each disc levels. Each volunteers did not discussed what they were checked on the degeneration grade, and only the author could observe the results of volunteers.

Quantitative Pfirrmann disc degeneration grade also checked as same manor using same three digitalized MR T2-weighted spine echo images (Fig. 1). Sheets of brief medical information about MR signal intensity and the sample areas to measure the signal intensity were provided to all volunteers (Fig. 2). After clear communication of checking quantitative Pfirmann disc degeneration grade, all volunteers checked the signal intensity of disc degeneration at the areas of NP, disc membrane, ligaments, fat, and air to modify the quantitative Pfirrmann disc degeneration grade. Each volunteers also did not discussed
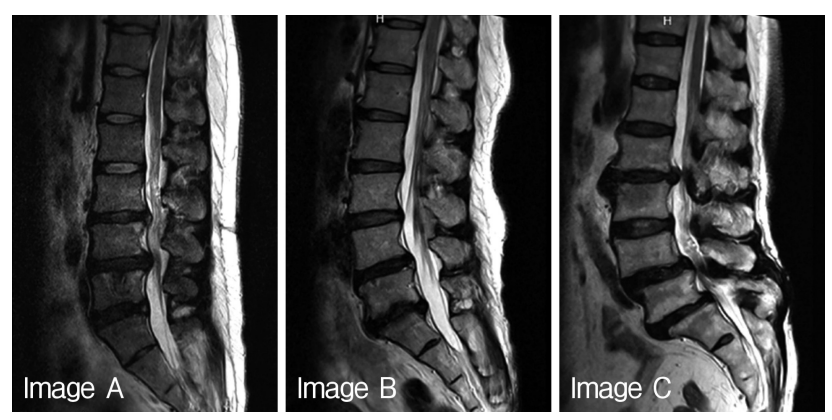

Fig. 1. Three digitalized magnetic resonance images provided to volunteers. of what they were checked on the signal intensity of each point, and only the author could observe the results.

The signal intensity of MR based image was checked using the medical image programs (PACSPLUS, Medical Standard, Seongnam, Korea). All images were midline positioned sagittal T2-weighted images which easily checkable the desired structures (Fig. 2). The signal intensity area of NP was defined as the different MR intensity of distinction area between inner and outer fibers of annulus at disc space. Although, the definition is very obscure such as the areas of NP, but, the recommend lesion was the homogenous center portion of NP with some distance from the bone edge. The signal intensity area of disc membrane was defined as the darkest area located in the middle anterior portion of disc space within 3-mm width. The signal intensity area of ligaments was defined as the most well visualized homogenous interspinous ligaments which located between the posterior spinous process. The signal intensity area of fat and air were defined as the most distinctive subcutaneous fat layer and air in posterior outside of body. All desired areas were checked the signal intensity using the function of region of interest (ROI) property in the image software program (PACSPLUS).

The results are expressed as I to V in Pfirrmann disc degenerative grade and the mean \pm standard deviation (SD) in quantitative Pfirrmann disc degeneration grade. Weighted kappa test was used to assess the interobserver reproducibility using Microsoft Excel 2013 and VassarStats (website for statistical computation http://vassarstats.net/kappa.html). A kappa $>0.800$ or $<0.200$ was considered as an excellent or poor agreement.

\section{RESULTS}

Total 225 Pfirrmann disc degeneration grades and 405

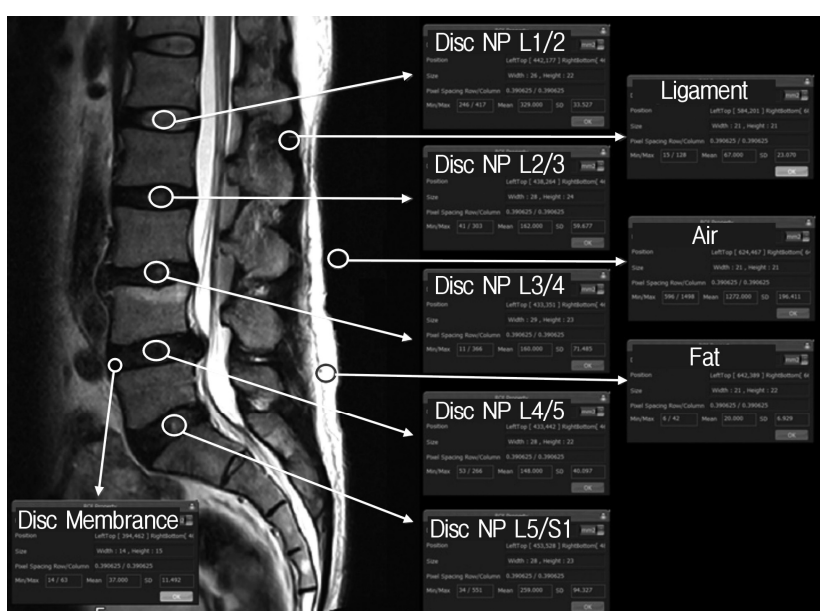

Fig. 2. Sample image to check magnetic resonance signal intensity of neucleus pulposus (NP), disc membrane, ligaments, fat, and air. 
Pfirrmann disc degeneration grades was resulted (Table 1). The result of Pfirrmann disc degeneration grade in MR images were grade I (6.66\%), grade II (46.67\%) or grade III (46.67\%) at the level of L1/2; grade II $(80 \%)$ or grade III $(20.00 \%)$ at L2/3; grade III (46.67\%) or grade IV (53.33\%) at L3/4; grade IV $(100 \%)$ at L4/5 and 5/S1 in image A: grade II (13.33\%) or grade III $(86.67 \%)$ at $\mathrm{L} 1 / 2$; grade II $(6.67 \%)$ or grade III $(93.33 \%)$ at $\mathrm{L} 2 / 3$; grade II $(6.67 \%)$, grade III $(80.00 \%)$ or grade IV (13.33\%) at L3/4; grade IV (100\%) at L4/5; grade IV $(40.00 \%)$ or grade $\mathrm{V}(60.00 \%)$ at $\mathrm{L} 5 / \mathrm{S} 1$ in image B: grade III (80.00\%) or grade IV (20.00\%) at L1/2; grade III (13.33\%), grade IV (66.67\%) or grade $\mathrm{V}(20.00 \%)$ at $\mathrm{L} 2 / 3$; grade III $(100.00 \%)$ at $\mathrm{L} 3 / 4$; grade IV (93.33\%) or grade V $(6.67 \%)$ at L4/5; and grade IV (26.67\%) or grade V (73.33\%) at L5/S1 in image C. Average interobserver agreement was "moderate" for all volunteers ranged from poor to excellent, with kappa values ranging from 0 to $1.000($ mean $\pm \mathrm{SD}, 0.575 \pm 0.251)$ (Table 2). Completely agreed levels of Pfirrmann disc degener- ation grade were observed only 4 levels (26.67\%), and relatively disagreement levels were observed in 11 levels; two different grades in 8 levels out of 15 levels (53.33\%) and three different grades in 3 levels out of 15 levels (20\%).

The result of Pfirrmann disc degeneration grade check by 4 medical doctors related to spinal disease was shown in Table 3. Completely agreed levels of Pfirrmann disc degeneration grade were only 6 levels (40.00\%), and relatively disagreement levels were observed in 9 levels with a difference of 1 grade. Although the interobserver agreement was more excellent in 4 medical doctors related to spinal disease compare to 15 volunteers, but it was also "moderate" agreement rates (mean \pm SD, $0.666 \pm 0.474$ ).

Quantitative Pfirmann disc degeneration showed relatively cluster distribution with the interobserver deviations. The checked ROIs in NP were $196.33 \pm 13.97$ at the level of L1/2; $155.00 \pm 8.41$ at $\mathrm{L} 2 / 3 ; 287.27 \pm 24.33$ at $\mathrm{L} 3 / 4 ; 132.73 \pm 16.93$ at $\mathrm{L} 4 / 5 ; 147.33 \pm 46.14$ at $5 / \mathrm{S} 1$ in image $\mathrm{A}: 312.33 \pm 12.17$ at $\mathrm{L} 1 / 2 ; 392.27 \pm 25.89$ at $\mathrm{L} 2 / 3 ; 212.67 \pm 21.87$ at $\mathrm{L} 3 / 4 ; 138.13$

Table 1. Pfirrmann disc degeneration grade and quantitative Pfirrmann disc degeneration grade by volunteers

\begin{tabular}{|c|c|c|c|c|c|c|c|c|c|c|}
\hline \multirow[b]{2}{*}{ Image } & \multirow{2}{*}{$\begin{array}{l}\text { Disc } \\
\text { level }\end{array}$} & \multicolumn{5}{|c|}{ Pfirrmann disc degeneration grade } & \multicolumn{4}{|c|}{ Quantitative Pfirrmann disc degeneration grade } \\
\hline & & I & II & III & IV & IV & $\begin{array}{l}\mathrm{NP} \text { over } \\
\text { membrane }\end{array}$ & $\begin{array}{l}\mathrm{NP} \text { over } \\
\text { ligament }\end{array}$ & $\mathrm{NP}$ over fat & $\mathrm{NP}$ over air \\
\hline \multirow[t]{5}{*}{ A } & $\mathrm{L} 1 / 2$ & $1(6.66)$ & $7(46.67)$ & $7(46.67)$ & - & - & $\begin{array}{l}6.10 \pm 1.18 \\
(4.24-8.03)\end{array}$ & $\begin{array}{r}4.83 \pm 1.22 \\
(2.81-6.83)\end{array}$ & $\begin{array}{r}0.26 \pm 0.03 \\
(0.22-0.33)\end{array}$ & $\begin{array}{c}8.22 \pm 1.94 \\
(6.08-11.48)\end{array}$ \\
\hline & $\mathrm{L} 2 / 3$ & - & $12(80.00)$ & $3(20.00)$ & - & - & $\begin{array}{c}7.66 \pm 1.56 \\
(5.38-10.13)\end{array}$ & $\begin{array}{r}6.07 \pm 1.57 \\
(3.42-8.62)\end{array}$ & $\begin{array}{c}0.33 \pm 0.04 \\
(0.27-0.42)\end{array}$ & $\begin{array}{c}10.38 \pm 2.77 \\
(7.06-16.41)\end{array}$ \\
\hline & $\mathrm{L} 3 / 4$ & - & - & $7(46.67)$ & $8(53.33)$ & - & $\begin{array}{r}4.17 \pm 1.00 \\
(2.69-5.83)\end{array}$ & $\begin{array}{r}3.30 \pm 0.92 \\
(1.58-4.91)\end{array}$ & $\begin{array}{r}0.18 \pm 0.03 \\
(0.13-0.22)\end{array}$ & $\begin{array}{l}5.56 \pm 1.24 \\
(3.98-8.24)\end{array}$ \\
\hline & $\mathrm{L} 4 / 5$ & - & - & - & $15(100)$ & - & $\begin{array}{r}2.71 \pm 0.60 \\
(1.74-3.78)\end{array}$ & $\begin{array}{r}2.14 \pm 0.56 \\
(1.19-3.21)\end{array}$ & $\begin{array}{r}0.12 \pm 0.01 \\
(0.10-0.15)\end{array}$ & $\begin{array}{l}3.65 \pm 0.94 \\
(2.51-5.67)\end{array}$ \\
\hline & $\mathrm{L} 5 / \mathrm{S} 1$ & - & - & - & $15(100)$ & - & $\begin{array}{l}1.88 \pm 0.48 \\
(1.11-2.76)\end{array}$ & $\begin{array}{l}1.50 \pm 0.48 \\
(0.76-2.23)\end{array}$ & $\begin{array}{r}0.08 \pm 0.01 \\
(0.06-0.10)\end{array}$ & $\begin{array}{r}2.52 \pm 0.68 \\
(1.40-3.85)\end{array}$ \\
\hline \multirow[t]{5}{*}{ B } & $\mathrm{L} 1 / 2$ & - & $2(13.33)$ & 13 (86.67) & - & - & $\begin{array}{l}5.55 \pm 1.41 \\
(2.80-7.51)\end{array}$ & $\begin{array}{r}2.90 \pm 0.46 \\
(12.37-3.98)\end{array}$ & $\begin{array}{r}0.21 \pm 0.03 \\
(0.17-0.27)\end{array}$ & $\begin{array}{l}8.54 \pm 2.58 \\
(3.72-11.81)\end{array}$ \\
\hline & $\mathrm{L} 2 / 3$ & - & $1(6.67)$ & $14(93.33)$ & - & - & $\begin{array}{l}5.11 \pm 1.35 \\
(2.57-7.06)\end{array}$ & $\begin{array}{r}2.67 \pm 0.49 \\
(1.90-3.66)\end{array}$ & $\begin{array}{r}0.19 \pm 0.02 \\
(0.15-0.23)\end{array}$ & $\begin{array}{l}7.87 \pm 2.45 \\
(3.42-11.0)\end{array}$ \\
\hline & $\mathrm{L} 3 / 4$ & - & $1(6.67)$ & $12(80.00)$ & $2(13.33)$ & - & $\begin{array}{l}5.46 \pm 1.37 \\
(2.65-7.70)\end{array}$ & $\begin{array}{l}2.87 \pm 0.56 \\
(2.07-4.10)\end{array}$ & $\begin{array}{r}0.20 \pm 0.03 \\
(0.15-0.27)\end{array}$ & $\begin{array}{c}8.38 \pm 2.43 \\
(3.52-12.10)\end{array}$ \\
\hline & $\mathrm{L} 4 / 5$ & - & - & - & $15(100)$ & - & $\begin{array}{r}2.33 \pm 0.70 \\
(1.07-3.76)\end{array}$ & $\begin{array}{r}1.24 \pm 0.35 \\
(0.77-2.00)\end{array}$ & $\begin{array}{r}0.09 \pm 0.01 \\
(0.07-0.12)\end{array}$ & $\begin{array}{l}3.56 \pm 1.10 \\
(1.42-5.90)\end{array}$ \\
\hline & L5/S1 & - & - & - & $6(40.00)$ & $9(60.00)$ & $\begin{array}{l}3.01 \pm 0.83 \\
(1.40-4.43)\end{array}$ & $\begin{array}{r}1.58 \pm 0.32 \\
(1.15-2.27)\end{array}$ & $\begin{array}{r}0.11 \pm 0.02 \\
(0.08-0.17)\end{array}$ & $\begin{array}{r}4.65 \pm 1.45 \\
(1.87-6.88)\end{array}$ \\
\hline \multirow[t]{5}{*}{$\mathrm{C}$} & $\mathrm{L} 1 / 2$ & - & - & $12(80.00)$ & $3(20.00)$ & - & $\begin{array}{r}2.23 \pm 0.56 \\
(1.32-3.05)\end{array}$ & $\begin{array}{r}3.20 \pm 0.72 \\
(1.47-4.41)\end{array}$ & $\begin{array}{r}1.74 \pm 0.32 \\
(1.20-2.26)\end{array}$ & $\begin{array}{r}7.06 \pm 1.45 \\
(3.76-9.41)\end{array}$ \\
\hline & $\mathrm{L} 2 / 3$ & - & - & $2(13.33)$ & $10(66.67)$ & $3(20.00)$ & $\begin{array}{l}1.77 \pm 0.47 \\
(1.05-2.48)\end{array}$ & $\begin{array}{r}2.52 \pm 0.60 \\
(1.16-3.43)\end{array}$ & $\begin{array}{r}1.37 \pm 0.23 \\
(1.02-1.72)\end{array}$ & $\begin{array}{l}5.57 \pm 1.10 \\
(2.98-7.32)\end{array}$ \\
\hline & $\mathrm{L} 3 / 4$ & - & - & $15(100)$ & - & - & $\begin{array}{r}3.28 \pm 0.93 \\
(1.79-4.52)\end{array}$ & $\begin{array}{l}4.66 \pm 0.97 \\
(2.07-5.73)\end{array}$ & $\begin{array}{r}2.54 \pm 0.42 \\
(3.07-1.79)\end{array}$ & $\begin{array}{c}10.24 \pm 1.75 \\
(6.12-12.91)\end{array}$ \\
\hline & $\mathrm{L} 4 / 5$ & - & - & - & $14(93.33)$ & $1(6.67)$ & $\begin{array}{l}1.51 \pm 0.45 \\
(0.82-2.30)\end{array}$ & $\begin{array}{c}2.17 \pm 0.57 \\
(1.09-2.94)\end{array}$ & $\begin{array}{r}1.18 \pm 0.25 \\
(0.72-1.63)\end{array}$ & $\begin{array}{r}4.78 \pm 1.12 \\
(2.45-6.64)\end{array}$ \\
\hline & $\mathrm{L} 5 / \mathrm{S} 1$ & - & - & - & $4(26.67)$ & $11(73.33)$ & $\begin{array}{l}1.69 \pm 0.74 \\
(0.72-3.15)\end{array}$ & $\begin{array}{r}2.37 \pm 0.88 \\
(1.26-3.71)\end{array}$ & $\begin{array}{l}1.30 \pm 0.45 \\
(0.73-1.98)\end{array}$ & $\begin{array}{r}5.32 \pm 1.93 \\
(1.92-7.78)\end{array}$ \\
\hline
\end{tabular}

Values are presented as number (\%) or mean \pm standard deviation (range).

$\mathrm{NP}$, nucleus pulposus. 
Table 2. Kappa values in interobserver agreement of Pfirrmann disc degeneration grade in each images

\begin{tabular}{ccccccccccccccc}
\hline \hline Image A & 1 & 2 & 3 & 4 & 5 & 6 & 7 & 8 & 9 & 10 & 11 & 12 & 13 & 14 \\
\hline 15 & 0.412 & 0.412 & 0.412 & 0.667 & 1.000 & 0.643 & 0.643 & 0.375 & 1.000 & 0.667 & 0.375 & 0.667 & 0.667 & 0.375 \\
14 & 0.333 & 0.333 & 0.118 & 0.118 & 0.375 & 0.643 & 0.643 & 1.000 & 0.375 & 0.118 & 1.000 & 0.118 & 0.118 \\
13 & 0.706 & 0.706 & 0.722 & 1.000 & 0.700 & 0.375 & 0.375 & 0.118 & 0.667 & 1.000 & 0.118 & 1.000 & \\
12 & 0.706 & 0.706 & 0.722 & 1.000 & 0.700 & 0.375 & 0.375 & 0.118 & 0.667 & 1.000 & 0.118 & \\
11 & 0.333 & 0.333 & 0.118 & 0.118 & 0.375 & 0.643 & 0.643 & 1.000 & 0.375 & 0.118 & & \\
10 & 0.706 & 0.706 & 0.722 & 1.000 & 0.700 & 0.375 & 0.375 & 0.118 & 0.667 & & & \\
9 & 0.412 & 0.412 & 0.412 & 0.667 & 1.000 & 0.643 & 0.643 & 0.375 & & & & \\
8 & 0.333 & 0.333 & 0.118 & 0.118 & 0.375 & 0.643 & 0.643 & & & & & \\
7 & 0.688 & 0.688 & 0.412 & 0.375 & 0.643 & 1.000 & & & & & & \\
6 & 0.688 & 0.688 & 0.412 & 0.375 & 0.643 & & & & & & & \\
5 & 0.412 & 0.412 & 0.412 & 0.667 & & & & & & & & \\
4 & 0.706 & 0.706 & 0.722 & & & & & & & & & \\
3 & 0.722 & 0.722 & & & & & & & & & & \\
2 & 1.000 & & & & & & & & & &
\end{tabular}

Average, 0.545; standard deviation, 0.265; range, 0.118-1.000.

\begin{tabular}{ccccccccccccccc}
\hline \hline Image B & 1 & 2 & 3 & 4 & 5 & 6 & 7 & 8 & 9 & 10 & 11 & 12 & 13 & 14 \\
\hline 15 & 0.250 & 0.500 & 0.250 & 0.000 & 0.474 & 0.500 & 0.211 & 0.250 & 0.500 & 0.250 & 0.250 & 0.500 & 0.500 & 0.500 \\
14 & 0.643 & 1.000 & 0.643 & 0.375 & 0.474 & 1.000 & 0.706 & 0.643 & 1.000 & 0.643 & 0.643 & 1.000 & 1.000 & \\
13 & 0.643 & 1.000 & 0.643 & 0.375 & 0.474 & 1.000 & 0.706 & 0.643 & 1.000 & 0.643 & 0.643 & 1.000 & \\
12 & 0.643 & 1.000 & 0.643 & 0.375 & 0.474 & 1.000 & 0.706 & 0.643 & 1.000 & 0.643 & 0.643 & \\
11 & 1.000 & 0.643 & 1.000 & 0.615 & 0.167 & 0.643 & 0.412 & 1.000 & 0.643 & 1.000 & & \\
10 & 1.000 & 0.643 & 1.000 & 0.615 & 0.167 & 0.643 & 0.412 & 1.000 & 0.643 & & & \\
9 & 0.643 & 1.000 & 0.643 & 0.375 & 0.474 & 1.000 & 0.706 & 0.643 & & & & \\
8 & 1.000 & 0.643 & 1.000 & 0.615 & 0.167 & 0.643 & 0.412 & & & & & \\
7 & 0.412 & 0.706 & 0.412 & 0.444 & 0.474 & 0.706 & & & & & & \\
6 & 0.643 & 1.000 & 0.643 & 0.375 & 0.474 & & & & & & & \\
5 & 0.167 & 0.474 & 0.167 & 0.412 & & & & & & & & \\
4 & 0.615 & 0.375 & 0.615 & & & & & & & & & \\
3 & 1.000 & 0.643 & & & & & & & & & & \\
2 & 0.643 & & & & & & & & & & & \\
\hline
\end{tabular}

Average, 0.627; standard deviation, 0.255; range, 0-1.000.

\begin{tabular}{rcccccccccccccc}
\hline \hline Image C & 1 & 2 & 3 & 4 & 5 & 6 & 7 & 8 & 9 & 10 & 11 & 12 & 13 & 14 \\
\hline 15 & 0.444 & 0.412 & 0.118 & 0.167 & 0.706 & 0.412 & 1.000 & 0.118 & 0.118 & 0.118 & 0.412 & 0.412 & 0.688 & 0.412 \\
14 & 0.688 & 1.000 & 0.667 & 0.333 & 0.706 & 1.000 & 0.412 & 0.667 & 0.706 & 0.667 & 1.000 & 1.000 & 0.688 \\
13 & 0.444 & 0.688 & 0.286 & 0.063 & 0.444 & 0.688 & 0.688 & 0.286 & 0.444 & 0.286 & 0.688 & 0.688 & \\
12 & 0.688 & 1.000 & 0.667 & 0.333 & 0.706 & 1.000 & 0.412 & 0.667 & 0.706 & 0.667 & 1.000 & \\
11 & 0.688 & 1.000 & 0.667 & 0.333 & 0.706 & 1.000 & 0.412 & 0.667 & 0.706 & 0.667 & & \\
10 & 0.375 & 0.412 & 1.000 & 0.615 & 0.444 & 0.412 & 0.118 & 1.000 & 0.444 & & & \\
9 & 0.375 & 0.706 & 0.444 & 0.118 & 0.375 & 0.706 & 0.118 & 0.444 & & & & \\
8 & 0.375 & 0.412 & 1.000 & 0.615 & 0.444 & 0.412 & 0.118 & & & & & \\
7 & 0.444 & 0.412 & 0.118 & 0.167 & 0.706 & 0.412 & & & & & & \\
6 & 0.688 & 1.000 & 0.667 & 0.333 & 0.706 & & & & & & & \\
5 & 0.688 & 0.706 & 0.444 & 0.412 & & & & & & & & \\
4 & 0.643 & 0.333 & 0.615 & & & & & & & & & \\
3 & 0.375 & 0.667 & & & & & & & & & & \\
2 & 0.688 & & & & & & & & & & & \\
\hline
\end{tabular}

Average, 0.554; standard deviation, 0.254; range, 0.063-1.000. 
Quantitative Pfirrmann Disc Degeneration Grade

Table 3. Interobserve correlation of Pfirrmann disc degeneration grade among 4 medical doctors related to spinal disease

\begin{tabular}{|c|c|c|c|c|c|c|}
\hline \multirow{2}{*}{ Image } & \multirow{2}{*}{ Disc Level } & \multicolumn{5}{|c|}{ Pfirrmann disc degeneration grade } \\
\hline & & I & II & III & IV & IV \\
\hline \multirow[t]{5}{*}{ A } & $\mathrm{L} 1 / 2$ & - & $1(25.00)$ & $3(75.00)$ & - & - \\
\hline & $\mathrm{L} 2 / 3$ & - & $2(50.00)$ & $2(50.00)$ & - & - \\
\hline & $\mathrm{L} 3 / 4$ & - & - & - & $4(100)$ & - \\
\hline & $\mathrm{L} 4 / 5$ & - & - & - & $4(100)$ & - \\
\hline & $\mathrm{L} 5 / \mathrm{S} 1$ & - & - & - & $4(100)$ & - \\
\hline \multirow[t]{5}{*}{ B } & $\mathrm{L} 1 / 2$ & - & $1(25.00)$ & $3(75.00)$ & - & - \\
\hline & $\mathrm{L} 2 / 3$ & - & $1(25.00)$ & $3(75.00)$ & - & - \\
\hline & $\mathrm{L} 3 / 4$ & - & $1(25.00)$ & $3(75.00)$ & - & - \\
\hline & $\mathrm{L} 4 / 5$ & - & - & - & $4(100)$ & - \\
\hline & $\mathrm{L} 5 / \mathrm{S} 1$ & - & - & - & $1(25.00)$ & $3(75)$ \\
\hline \multirow[t]{5}{*}{ C } & $\mathrm{L} 1 / 2$ & - & - & $2(50.00)$ & $2(50.00)$ & - \\
\hline & $\mathrm{L} 2 / 3$ & - & - & - & $2(50.00)$ & $2(50.00)$ \\
\hline & $\mathrm{L} 3 / 4$ & - & - & $4(100)$ & - & - \\
\hline & $\mathrm{L} 4 / 5$ & - & - & - & $4(100)$ & - \\
\hline & $\mathrm{L} 5 / \mathrm{S} 1$ & - & - & - & $1(25.00)$ & $3(75.00)$ \\
\hline
\end{tabular}

Values are presented as number (\%).

\pm 7.34 at $\mathrm{L} 4 / 5 ; 96.00 \pm 15.19$ at $\mathrm{L} 5 / \mathrm{S} 1$ in image B: $254.40 \pm$ 12.23 at $\mathrm{L} 1 / 2 ; 225.67 \pm 14.42$ at $\mathrm{L} 2 / 3 ; 241.67 \pm 14.54$ at $\mathrm{L} 3 / 4$; $103.07 \pm 15.21$ at $\mathrm{L} 4 / 5$; and $134.07 \pm 22.08$ at $\mathrm{L} 5 / \mathrm{S} 1$ in image C. The checked quantified Pfirrmann disc degeneration grade based on disc membrane signal intensity in MR images were $6.10 \pm 1.18$ (range, 4.24-8.03) at the level of L1/2; 7.66 \pm 1.56 (range, 5.38-10.13) at $\mathrm{L} 2 / 3 ; 4.17 \pm 1.00$ (range, 2.69-5.83) at $\mathrm{L} 3 / 4 ; 2.71 \pm 0.60$ (range, $1.74-3.78$ ) at $\mathrm{L} 4 / 5 ; 1.88 \pm 0.48$ (range, $1.11-2.76)$ at $5 / \mathrm{S} 1$ in image A: $5.55 \pm 1.41$ (range, $2.80-7.51$ ) at $\mathrm{L} 1 / 2 ; 5.11 \pm 1.35$ (range, 2.57-7.06) at $\mathrm{L} 2 / 3 ; 5.46 \pm 1.37$ (range, 2.65-7.70) at $\mathrm{L} 3 / 4 ; 2.33 \pm 0.70$ (range, 1.07-3.76) at $\mathrm{L} 4 / 5 ; 3.01 \pm 0.83$ (range, $1.40-4.43$ ) at $\mathrm{L} 5 / \mathrm{S} 1$ in image $\mathrm{B}: 2.23 \pm$ 0.56 (range, $1.32-3.05$ ) at L1/2; $1.77 \pm 0.47$ (range, 1.05-2.48) at $\mathrm{L} 2 / 3 ; 3.28 \pm 0.93$ (range, $1.79-4.52$ ) at $\mathrm{L} 3 / 4 ; 1.51 \pm 0.45$ (range, 0.82-2.30) at L4/5; and 1.69 \pm 0.74 (range, 0.72-3.15) at L5/S1 in image C (Table 1 and Fig. 3). Average interobserver agreement was "moderate (mean $\pm \mathrm{SD}, 0.575 \pm 0.251$ )" from poor to excellent as kappa 0 to 1.000 . The distribution of quantitative Pfirmann disc degeneration were $0.41-1.56$ at the ratio of NP and disc membrane; $0.32-1.57$ at the ratio of NP and ligaments; $0.01-0.45$ at the ratio of NP and fat; and 0.682.77 at the ratio of NP and air (Table 1 and Fig. 3). Quantitative Pfirrmann disc degeneration is too clustered in the base of fat and too distributed in the base of fat, but it showed relatively good cluster and distribution in the base of disc membrane and ligaments indicating that the proposed grading system has good discrimination ability.

\section{DISCUSSION}

Intervertebral disc degeneration plays an important role in low back pain and that severity of disc degeneration is broadly associated with severity of chronic symptomatology ${ }^{10,17,27}$. The intervertebral disc is a cushion-like structure, and it consists of the NP, the annulus fibrosus, and the cartilaginous endplates $^{6}$. The NP is composed of abundant sulfated glycosaminoglycans in a loose network of type II collagen ${ }^{10)}$. The annulus fibrosus forms the outer boundary of the disc and is made up of coarse type I collagen fibers ${ }^{10)}$. The proteoglycans of the nucleus osmotically exert a swelling pressure, which support spinal compressive loads ${ }^{10)}$. During the disc degeneration, loss of proteoglycans and collagen type II is observed ${ }^{2)}$. The slow poroelastic behavior is mediated by fluid flow, due to the binding and releasing of water by the proteoglycans in the nucleus $^{19)}$. The bound water in the nucleus generates an intradiscal osmotic pressure, which separates the vertebrae and tensions the annulus fibrosus $1,2,3,5,11,26,27$ ).

A common definition of DDD is based on the appearance of the intervertebral disc on $\mathrm{MRI}^{10,13,14,20)}$, because the signal loss of the disc on a T2-weighted image reflects a decrease of both proteoglycans and water content in the disc ${ }^{13)}$. Depending on the stage of degeneration, structural changes in the disc and loss of disc height can be visualized on $\mathrm{MRI}^{3,14,18,20)}$. Based on proton density, water content and chemical environment, MR depicts disc hydration and morphology ${ }^{24,28)}$. Analysis of the biochemical changes on the same specimens has suggested that MR reflects the proteoglycan content of the nucleus more closely than gross tissue morphology ${ }^{25}$. The brightness of the nucleus has been shown to correlate directly with the proteoglycan concentration, but not with the water or collagen content $^{10,16)}$. The signal intensity of the disc in relation to chemical composition and histologic changes has been stud- 

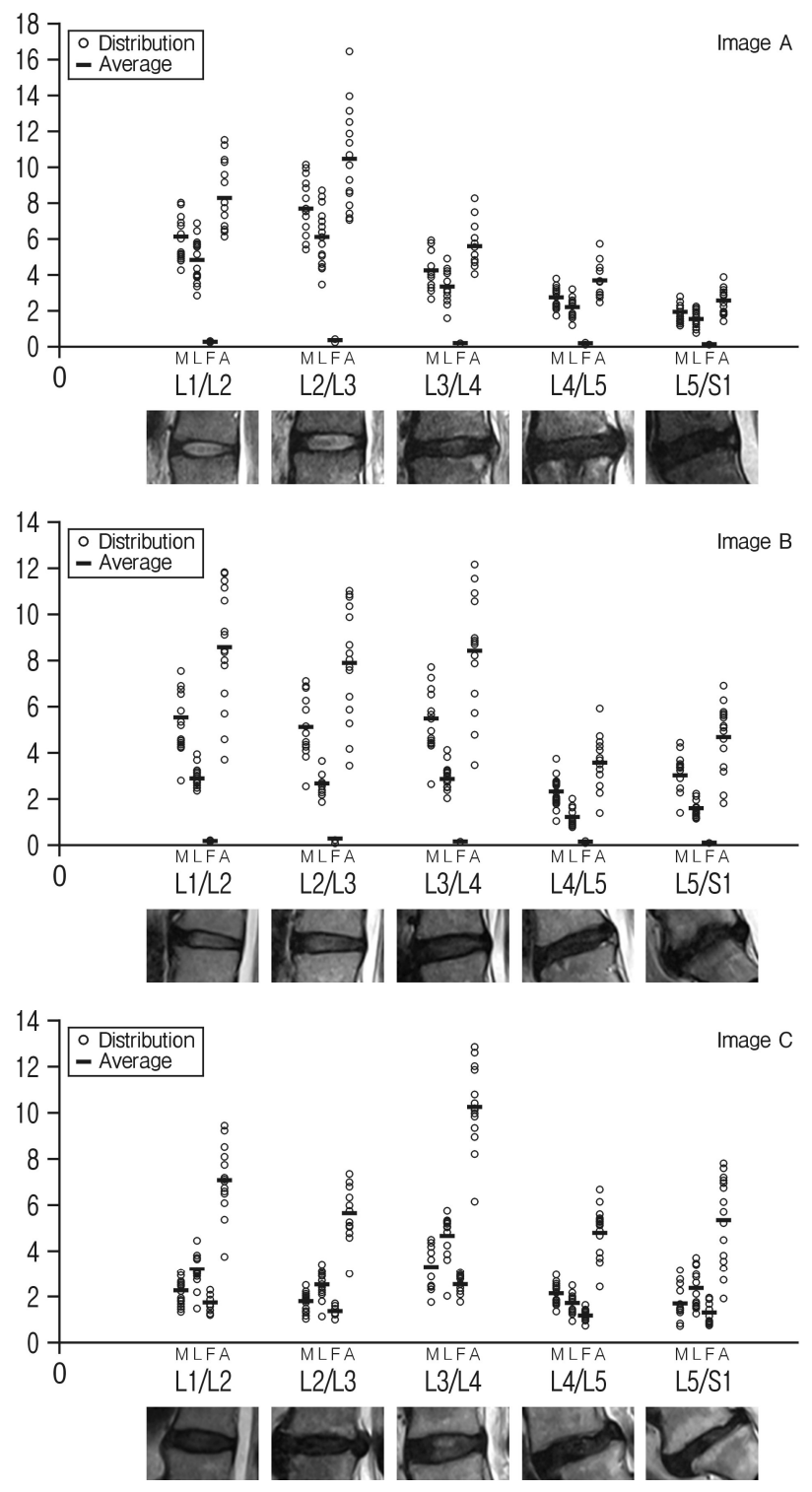

Fig. 3. The distribution of quantitative Pfirrmann disc degeneration grade in images ( $\mathrm{M}$, the ratio of $\mathrm{NP}$ and disc membrane; $\mathrm{L}$, the ratio of NP and ligaments; F, the ratio of NP and fat; and $\mathrm{A}$, the ratio of NP and air). NP, neucleus pulposus.

ied $^{18,20,24)}$. The signal characteristics of the disc in T2-weighted MRIs reflect changes caused by aging or degeneration ${ }^{14,16,18,22)}$. Disc degeneration is seen as a reduction in signal of the NP and inner fibers of the annulus ${ }^{10)}$. This decreases the sharp distinction between the inner and outer fibers of the annulus ${ }^{10)}$. With more severe disc degeneration, there is no demarcation between the inner and outer fibers of the annulus, and disc height decreases ${ }^{10}$. Early loss of signal intensity is not accompanied by a reduction in disc height, although later changes do show concordant loss of disc height ${ }^{9}$. Variations in disc hydration or composition can be detected noninvasively by quantitative MRI with sufficient accuracy ${ }^{4)}$.
A number of morphologic grading systems for lumbar disc degeneration have been proposed. Pfirmann et al. ${ }^{18)}$ applied a grading system for disc degeneration based on MR signal intensity, disc structure, distinction between nucleus and annulus and disc height. The frequency of disagreement in discriminating grades was fairly uniform among the different levels. The interobserver agreements of this grading system were substantial to excellent ${ }^{10,13,18)}$. But, some limitations of this grading system were also reported. First, Pfirrmann disc degeneration grade proved relatively nondiscriminatory when examining more elderly subjects. Second, some ambiguity was encountered, based on the images and description provided, in categorizing disc degeneration as either one level or another ${ }^{10)}$. So, some studies suggested that 8-level Pfirrmann grading system rather than 5-level Pfirrmann grading system for disc degeneration to assess disc degeneration in the elderly spine ${ }^{10)}$.

In this study, quantitative Pfirrmann disc degeneration grade was checked by using signal intensity of disc degeneration at the areas such as NP and adjacent structures. Several experimental studies have proven a good correlation of T2 relaxation time values and water content in intervertebral disc tissue $^{23,24,29)}$. The signal intensity area of NP was defined as the different MR intensity of distinction area between inner and outer fibers of annulus at disc space. Also, the definition of signal intensity area of $\mathrm{NP}$ is very obscure, signal intensity area of different NP regions did not show different $\mathrm{T} 2$ values in another quantitative morphologic study ${ }^{23)}$. The geometrical center of the intervertebral area was matched to the center of intensity of the NP, and it also represents highest degree of sensitivity for quantifying intervertebral disc signal intensity on T2-weighted image ${ }^{14}$. Morphologic Pfirrmann disc degeneration is based on the distinct between NP and disc membrane, quantitative Pfirrmann disc degeneration based on the ratio between $\mathrm{NP}$ and adjacent structures could be helpful. In this study, quantitative Pfirrmann disc degeneration in the base of fat is too clustered and too distributed in the base of fat, but it showed relatively good cluster and distribution in the base of disc membrane and ligaments indicating that the proposed grading system has good discrimination ability. This tendency also observed in another study with similar values of annulus fibrosus between the different morphologic Pfirrmann disc degeneration grades from I to IV ${ }^{23)}$.

The result in this study presented the poor to excellent interobserver agreement in Pfirrmann disc degeneration grade with kappa values ranging $0.575 \pm 0.251$ (mean $\pm S D$ ) (Table 1). Indeed, the interobserver agreement in 4 medical doctors related to spinal disease also showed similar agreement rates $0.666 \pm$ 0.474 (mean \pm SD). Completely agreed levels of Pfirrmann disc degeneration grade were only 4 levels (26.67\%), and the disagreement levels were observed in 11 levels (73.33\%). But, quantitative Pfirmann disc degeneration showed relatively cluster distribution. Quantitative grading showed relatively good cluster and distribution in the base of disc membrane (SD between 0.41-1.56) and ligaments (SD between 0.32-1.57) indicating that the proposed grading system has good discrimina- 
tion ability. This quantitative measuring also provided additional advantage for checking DDD in the serial personal MR images. Disc degeneration is a continuum rather than a step-bystep process ${ }^{10)}$. So, 5 -level Pfirrmann grading system could provide only nondiscriminatory information when the DDD is not typical to pass the grading scale, but quantitative Pfirrmann grading system could provide continuum information about DDD. Indeed, a stepwise decrease in NP signal intensity values from Pfirrmann grade I to IV, with highly significant differences between each grade ${ }^{23)}$.

Although, quantitative Pfirrmann grading system which proposed in this study was novel concept to DDD, but it has also some limitations. First, we could not check the interobserver correlation of this system, so we cannot clearly insist that quantitative Pfirrmann grading system is more superior to 5 -level Pfirrmann grading system. Because, the comparison is not possible between moderate correlation of 5-level Pfirrmann grading system and quantitative result of quantitative Pfirrmann grading system. Second, quantitative Pfirmann grading system provided useful information about the quality of NP, but it cannot provide the reduction in disc height which is usually observed in severe disc degeneration. As the result indicated, grades 4 and 5 DDD in 5-level Pfirrmann grading system showed similar quantitative result of quantitative Pfirrmann grading system. So, it was assumed that grades 4 and 5 DDD is not different disc pathology or additional disc height information should be combined in quantitative Pfirrmann grading system. Third, the ROI of NP or other structures also could be different to different observers. In this study, the definition is very obscure such as the areas of NP, but, this difference of ROI could be overcome by detailed definition such as the center of NP with distance to bone edge. But, nevertheless this limitation, quantitative Pfirrmann disc degeneration grade is expected that it can provide more reliable information about DDD. Indeed, the present method could be useful for longitudinal tracking of intervertebral disc degeneration with sufficient reproducibility ${ }^{14)}$. Recently, a more sensitive biochemical imaging of intervertebral discs with glycosaminoglycan chemical exchange saturation transfer MRI is developed and investigated to overcome the limitation of the morphological MRI which were considered as well established and the most sensitive method for the clinical assessment of disc degeneration ${ }^{21)}$. So, combined quantitative morphological evaluation and qualitative biochemical assessment could be useful for the evaluation of disc degeneration and its clinical grading in the future study.

\section{CONCLUSION}

Pfirrmann disc degeneration grade showed the limitation of different interobserver results, but this limitation could be overcome by using quantitative techniques of MR signal intensity. Quantitative Pfirrmann grading system seems to be able to characterize different degrees of disc degeneration quantitatively. The reproducibility of quantitative Pfirrmann grading system is sufficient to encourage the use of this method in future investigations, particularly for longitudinal studies. Further evaluation is needed to access its advantage and reliabilities.

\section{CONFLICT OF INTEREST}

No potential conflict of interest relevant to this article was reported.

\section{ACKNOWLEDGMENTS}

The author specially thanks to Chang Hyun Oh, MD, PhD who modified this article with great support.

\section{REFERENCES}

1. Adams MA, Roughley PJ: What is intervertebral disc degeneration, and what causes it? Spine (Phila Pa 1976) 31:2151-2161, 2006

2. Antoniou J, Steffen T, Nelson F, Winterbottom N, Hollander AP, Poole RA, et al: The human lumbar intervertebral disc: evidence for changes in the biosynthesis and denaturation of the extracellular matrix with growth, maturation, ageing, and degeneration. J Clin Invest 98:996-1003, 1996

3. Benneker LM, Heini PF, Anderson SE, Alini M, Ito K: Correlation of radiographic and MRI parameters to morphological and biochemical assessment of intervertebral disc degeneration. Eur Spine J 14:27-35, 2005

4. Boos N, Wallin A, Schmucker T, Aebi M, Boesch C: Quantitative MR imaging of lumbar intervertebral disc and vertebral bodies: methodology, reproducibility, and preliminary results. Magn Reson Imaging 12:577-587, 1994

5. Brinckmann P, Grootenboer H: Change of disc height, radial disc bulge, and intradiscal pressure from discectomy. An in vitro investigation on human lumbar discs. Spine (Phila Pa 1976) 16: 641-646, 1991

6. Chan SC, Ferguson SJ, Gantenbein-Ritter B: The effects of dynamic loading on the intervertebral disc. Eur Spine J 20:1796-1812, 2011

7. Emanuel KS, Vergroesen PP, Peeters M, Holewijn RM, Kingma I, Smit TH: Poroelastic behaviour of the degenerating human intervertebral disc: a ten-day study in a loaded disc culture system. Eur Cell Mater 29:330-340, 2015

8. Farshad-Amacker NA, Farshad M, Winklehner A, Andreisek G: MR imaging of degenerative disc disease. Eur J Radiol 84:17681776, 2015

9. Frobin W, Leivseth G, Biggemann M, Brinckmann P: Vertebral height, disc height, posteroanterior displacement and dens-atlas gap in the cervical spine: precision measurement protocol and normal data. Clin Biomech (Bristol, Avon) 17:423-431, 2002

10. Griffith JF, Wang YX, Antonio GE, Choi KC, Yu A, Ahuja AT, et al: Modified Pfirrmann grading system for lumbar intervertebral disc degeneration. Spine (Phila Pa 1976) 32:E708-712, 2007 11. Hwang D, Gabai AS, Yu M, Yew AG, Hsieh AH: Role of load 
history in intervertebral disc mechanics and intradiscal pressure generation. Biomech Model Mechanobiol 11:95-106, 2012

12. Kettler A, Wilke HJ: Review of existing grading systems for cervical or lumbar disc and facet joint degeneration. Eur Spine J 15:705-718, 2006

13. Miyazaki M, Hong SW, Yoon SH, Morishita Y, Wang JC: Reliability of a magnetic resonance imaging-based grading system for cervical intervertebral disc degeneration. J Spinal Disord Tech 21:288-292, 2008

14. Modic MT, Masaryk TJ, Ross JS, Carter JR: Imaging of degenerative disk disease. Radiology 168:177-186, 1988.

15. Nagashima $M$, Abe $H$, Amaya $K$, Matsumoto $H$, Yanaihara $H$, Nishiwaki Y, et al: A method for quantifying intervertebral disc signal intensity on T2-weighted imaging. Acta Radiol 53:10591065, 2012

16. Pearce RH, Thompson JP, Bebault GM, Flak B: Magnetic resonance imaging reflects the chemical changes of aging degeneration in the human intervertebral disk. J Rheumatol Suppl 27:4243, 1991

17. Peterson CK, Bolton JE, Wood AR: A cross-sectional study correlating lumbar spine degeneration with disability and pain. Spine (Phila Pa 1976) 25:218-223, 2000

18. Pfirrmann CW, Metzdorf A, Zanetti M, Hodler J, Boos N: Magnetic resonance classification of lumbar intervertebral disc degeneration. Spine (Phila Pa 1976) 26:1873-1878, 2001

19. Sato K, Kikuchi S, Yonezawa T: In vivo intradiscal pressure measurement in healthy individuals and in patients with ongoing back problems. Spine (Phila Pa 1976) 24:2468-2474, 1999

20. Schiebler ML, Camerino VJ, Fallon MD, Zlatkin MB, Grenier N, Kressel HY: In vivo and ex vivo magnetic resonance imaging evaluation of early disc degeneration with histopathologic correlation. Spine (Phila Pa 1976) 16:635-640, 1991

21. Schleich C, Müller-Lutz A, Zimmermann L, Boos J, Schmitt B, Wittsack HJ, et al: Biochemical imaging of cervical interverte- bral discs with glycosaminoglycan chemical exchange saturation transfer magnetic resonance imaging: feasibility and initial results. Skeletal Radiol 45:79-85, 2016

22. Sether LA, Yu S, Haughton VM, Fischer ME: Intervertebral disk: normal age-related changes in MR signal intensity. Radiology 177:385-388, 1990

23. Stelzeneder D, Welsch GH, Kovács BK, Goed S, PaternostroSluga T, Vlychou M, et al: Quantitative T2 evaluation at 3.0 T compared to morphological grading of the lumbar intervertebral disc: a standardized evaluation approach in patients with low back pain. Eur J Radiol 81:324-330, 2012

24. Tertti M, Paajanen H, Laato M, Aho H, Komu M, Kormano $\mathrm{M}$ : Disc degeneration in magnetic resonance imaging. A comparative biochemical, histologic, and radiologic study in cadaver spines. Spine (Phila Pa 1976) 16:629-634, 1991

25. Thompson JP, Pearce RH, Schechter MT, Adams ME, Tsang IK, Bishop PB: Preliminary evaluation of a scheme for grading the gross morphology of the human intervertebral disc. Spine (Phila Pa 1976) 15:411-415, 1990

26. Tomaszewski KA, Saganiak K, Gladysz T, Walocha JA: The biology behind the human intervertebral disc and its endplates. Folia Morphol (Warsz) 74:157-168, 2015

27. Vergroesen PP, Kingma I, Emanuel KS, Hoogendoorn RJ, Welting TJ, van Royen BJ, et al: Mechanics and biology in intervertebral disc degeneration: a vicious circle. Osteoarthritis Cartilage 23:1057-1070, 2015

28. Viikari-Juntura E, Raininko R, Videman T, Porkka L: Evaluation of cervical disc degeneration with ultralow field MRI and discography. An experimental study on cadavers. Spine (Phila Pa 1976) 14:616-619, 1989

29. Watanabe A, Benneker LM, Boesch C, Watanabe T, Obata T, Anderson SE: Classification of intervertebral disk degeneration with axial T2 mapping. AJR Am J Roentgenol 189:936-942, 2007 